\title{
ARISTOTLE'S FOUNDATIONALISM
}

\author{
Breno Andrade Zuppolini \\ UNICAMP
}

\begin{abstract}
Resumo: Para Aristóteles, conhecimento demonstrativo é o resultado do que ele denomina 'aprendizado intelectual', processo em que o conhecimento da conclusão depende de um conhecimento prévio das premissas. Dado que demonstrações são, em última instância, baseadas em princípios indemonstráveis (cujo conhecimento é denominado 'voṽc'), Aristóteles é frequentemente retratado como promovendo uma doutrina fundacionista. Sem contestar a nomenclatura, tentarei mostrar que o 'fundacionismo' de Aristóteles não deve ser entendido como uma teoria racionalista da justificação epistêmica, como se os primeiros princípios da ciência pudessem ser conhecidos enquanto tais independentemente de suas conexões explanatórias com proposições demonstráveis. Argumentarei que conhecer os primeiros princípios enquanto tais envolve conhecê-los como explicações de outras proposições científicas. Explicarei, então, de que modo conhecimento noético e conhecimento demonstrativo são, em certo sentido, estados cognitivos interdependentes - ainda que o conceito de voṽ $\varsigma$ se mantenha distinto de (e, nas palavras de Aristóteles, mais 'preciso' do que) conhecimento demonstrativo.
\end{abstract}

Palavras-chave: Aristóteles; fundacionismo; ciência; demonstração.

\begin{abstract}
For Aristotle, demonstrative knowledge is the result of what he calls intellectual learning, a process in which the knowledge of a conclusion depends on previous knowledge of the premises. Since demonstrations are ultimately based on indemonstrable principles (the knowledge of which is called 'voũ $\zeta$ '), Aristotle is often described as advancing a foundationalist doctrine. Without disputing the nomenclature, I shall attempt to show that Aristotle's 'foundationalism' should not be taken as a rationalist theory of epistemic justification, as if the first principles of science could be known as such independently of their explanatory connections to demonstrable propositions. I shall argue that knowing first principles as such involves knowing them as explanatory of other scientific propositions. I shall then explain in which way noetic and demonstrative knowledge arein a sense interdependent cognitive states - even though voũ $\varsigma$ remains distinct from (and, in Aristotle's words, more 'accurate' than) demonstrative knowledge.
\end{abstract}

Keywords: Aristotle; foundationalism; science; demonstration.

Aristotle is often thought to have accepted some form of 'foundationalism.' In the Posterior Analytics (hereafter APo), he focuses on the

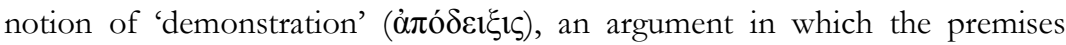

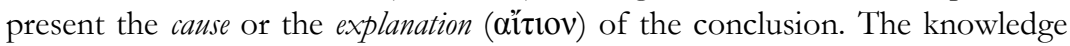
we acquire through demonstrations is the result of what Aristotle calls

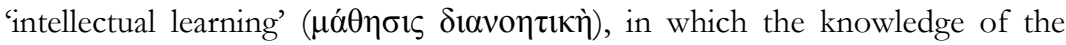

1 See Irwin (1988, 130-131); Ferejohn (1991, 4-5; 2009, 66); Goldin (2013). 
conclusion is based on previous knowledge of the premises ( $A P_{0} \mathrm{I} 1,71^{\mathrm{a} 1}-9$ ). According to him, if the ordered pair $\langle\boldsymbol{\Pi}, \mathbf{c}\rangle$ is a demonstration - where $\Pi$ is a set of premises and $\mathbf{c}$ is the conclusion -, the set $\boldsymbol{\Pi}$ is finite, and $\mathbf{c}$ is obtained through finitely many steps. If so, there is a subset of $\boldsymbol{\Pi}$ - let us say $\boldsymbol{\Pi} \mathbf{\prime}-$ such that, whereas all the members of $\boldsymbol{\Pi}^{\prime}$ are indemonstrable, all the other premises in $\Pi$ (and consequently c) are directly or indirectly demonstrated from them. ${ }^{2}$ Although these basic premises are indemonstrable (APo I 2, 71 ${ }^{\mathrm{b}} 26-7$ ), we do have knowledge of them by a non-demonstrative cognitive state called 'intelligence' (voũ s, APo II 19, 100 5-17).

In $A P_{0}$ I 3, Aristotle discusses two possible reactions to the principle that every intellectual learning (including learning by demonstration) comes from pre-existing knowledge. One of them is to be come sceptical about the possibility of demonstrative knowledge on the grounds that demonstrating is a process that leads to infinite regress. The other is to accept circular explanations as authentic demonstrations and thus maintain that demonstrative knowledge is possible. Aristotle agrees with the second view with regard to the possibility of demonstrative knowledge, but denies that circular demonstrations are properly explanatory. According to him, the relation '...being explanatory of...' is asymmetrical: if a proposition $\mathbf{p}_{1}$ is explanatory of $\mathbf{p}_{2}$ (and $\mathbf{p}_{1}$ is a premise from which $\mathbf{p}_{2}$ is demonstrated), $\mathbf{p}_{2}$ is not explanatory of $\mathbf{p}_{1}$ (and hence is not a premise from which $\mathbf{p}_{1}$ can be demonstrated). ${ }^{3}$ Similarly, Aristotle agrees with the first view to some extent: an infinite demonstration could not produce knowledge insofar as we could not survey its premises with thought. ${ }^{4}$ However, that does not mean that demonstrative knowledge is impossible. Aristotle prefers to reject their common assumption that all premises in a demonstration must be themselves known by demonstration.

Thus, it is not without reason that the word 'foundationalism' has been used to describe Aristotle's conception of scientific knowledge. The very idea of there being basic indemonstrable principles in science is commonly associated with foundationalist doctrines. It is far from clear, however, how exactly Aristotle thinks we can learn 'by demonstration. ${ }^{5}$ Depending on how this process of learning is specified, the epistemological alternative Aristotle offers in APo I 3 can be seriously misinterpreted, rendering his theory inconsistent and unattractive. Without disputing the nomenclature, I shall attempt to show that the 'foundationalism' endorsed in APo I 3 should not be taken as a theory on epistemic justification. That is to say, Aristotle does not

${ }^{2} A P o$ I $3,72^{\text {b } 18-25 ; ~ I ~ 19, ~ 82 a ~ 2-9 ; ~ I ~ 22, ~ 83 ~} 24-84^{\text {b }} 2$.

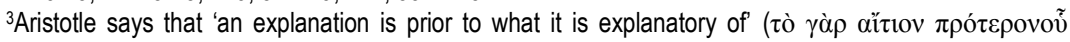

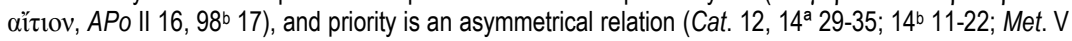
11, 1019a 1-4; VII 10, 1034 b 30-32; 1035 b 6-7). See also APo I 3, 72 $25-73^{\text {a }} 20 ; A P r \| l 6$.

${ }^{4} A P$ o I $3,72^{\mathrm{b}} 7-15 ;$ I 22, 82 ${ }^{\mathrm{b}} 37-83^{\mathrm{a}} 1 ;$; 83 $6-7,83^{\mathrm{b}} 32$ - 84a 6.

${ }^{5}$ APo I 18, 81a40; Metaphysics I 9, 992 ${ }^{\mathrm{b}}$ 30-33. 
endorse the view that having demonstrative knowledge of $\mathbf{c}$ is to justify the belief that $\mathbf{c}$ is true by showing that it follows (deductively) from self-evident premises that can be known without any previous justification. As I shall argue, such (rationalist) view contradicts Aristotle's own (empiricist) account of how we acquire knowledge of first principles. Like demonstrative knowledge, voṽ $\zeta$ is also the result of intellectual learning, and hence requires pre-existing knowledge (and ultimately perceptual knowledge). Rather, to be an Aristotelian foundationalist is to accept the existence of primary explanatory factors in the world, also known as 'essences.' I shall follow other commentators and argue that the status of any premise $\mathbf{p}$ as a first principle does not rely (primarily) on a feature that $\mathbf{p}$ has in itself (such as being selfevident or analytically true), but depends on $\mathbf{p}$ having or not having explanatory relations with other propositions within the science in question. Correspondingly, what counts as an essence for Aristotle cannot be identified as such independently of its status as a cause. I shall then explain in which way this picture implies that voũ $\zeta$ and demonstrative knowledge are in a sense interdependent cognitive states - even though, voũ $\varsigma$ remains distinct from (and, in Aristotle's words, more 'accurate' than) demonstrative knowledge.

\section{A Rationalist Interpretation of Aristotle's Foundationalism}

According to the common contemporary view, someone learns something through a deductive argument $\langle\Pi, \mathbf{c}\rangle$ when she, without previously knowing $\mathbf{c}$ to be true, finds it to be true by (i) knowing in advance that the premises in $\boldsymbol{\Pi}$ are true and (ii) realizing that $\mathbf{c}$ is a logical consequence of $\boldsymbol{\Pi}$. Naturally, this view has been imputed to Aristotle and his theory of demonstration:

\footnotetext{
Aristotle presented a general truth-and-consequence conception of demonstration meant to apply to all demonstrations. According to him, a demonstration, which normally proves a conclusion not previously known to be true, is an extended argumentation beginning with premises known to be truths and containing a chain of reasoning showing by deductively evident steps that its conclusion is a consequence of its premises (CORCORAN, 2009, 1).
}

In the same vein, some interpreters believed that Aristotle's foundationalism implies that the indemonstrable principles of science are selfevident premises whose truth is known by non-inferential procedures and from which the scientist infers and therefore learns other propositions not 
previously known to be true. ${ }^{6}$ This interpretation might seem congenial to the fact that, in his theory, demonstrations proceed from definitions: ${ }^{7}$

The principles of demonstrations are definitions, and it has been proved earlier that there will not be demonstrations of principles - either the principles will be demonstrable and there will be principles of principles, and this will continue ad infinitum, or else the primitives will be indemonstrable definitions [APo II 3, 90 24-7; Barnes 1993].

Certain definitional statements (usually called 'nominal definitions') are meant to fix the meaning of the terms used in scientific discourse. Such statements can be described as analytic and knowable a priori. Hence, their status as first principles would rely primarily on self-evidence. According to this view, the intuitive knowledge we have of propositions of this kind is what Aristotle calls ' $v o \tilde{\varsigma} \varsigma$ ', from which $\dot{\varepsilon} \pi \iota \tau \eta \dot{\mu \eta} \dot{\alpha} \pi \circ \delta \varepsilon \iota \kappa \tau \iota \kappa \eta$ is (deductively) derived. Since these two cognitive states are the highest forms of knowledge (APo II 19, 100 5 5-9), it is easy to understand why Aristotle was once seen as 'the paradigm of an extreme rationalist', who would recognise a posteriori truths as knowable (if at all) 'only in a debased sense of knowledge."

However, if this is the process of intellectual learning by which we acquire demonstrative knowledge, Aristotle's foundationalist project seems blatantly inconsistent. As we saw, if $\langle\boldsymbol{\Pi}, \mathbf{c}\rangle$ is a demonstration, the set of premises $\Pi$ reveals the appropriate explanation of the conclusion $\mathbf{c}$. However, the philosopher believes we cannot start pursuing the explanans without knowing in advance that the corresponding explanandum is true (see APo II 12 ). Thus, how could a demonstration $\langle\boldsymbol{\Pi}, \mathbf{c}\rangle$ enable us to learn $\mathbf{c}$ in the first place if knowing that $\mathbf{c}$ is true is a necessary condition for investigating the very explanation the set $\Pi$ is expected to display??

The apparent inadequacy of Aristotle's account seems to lie with his assumption that the explanans is revealed by the premises of a demonstration, whereas the explanandum is found in the conclusion. Such assumption seems to violate our modern intuitions about how knowledge of causal or explanatory relations is acquired. For instance, modern philosophers of science such as Charles Pierce distinguish between three kinds of arguments: ${ }^{10}$

${ }^{6}$ See, for instance, Scholz (1975); Irwin (1988, 130-131).

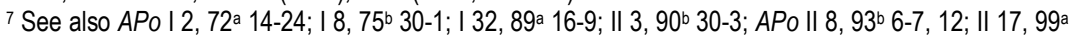
3-5, 21-6.

${ }^{8}$ Frede $(1996,157-158)$.

9 Barnes (1969, 146);Burnyeat (1981, 116-7). For a helpful exposition of the problem, see Bronstein (2014, 13; 2016, 32-33).

10 See Pierce (Collected Papers; 2. 622-623) 


\section{Deduction:}

All the beans from this bag are white, These beans are from this bag

These beans are white

\section{Induction:}

These beans are from this bag, These beans are white

All the beans from this bag are white

\section{Abduction:}

All the beans from this bag are white, These beans are white

These beans are from this bag

In a deductive argument such as the one formulated above, the premises state a general rule (all the beans from this bag are white) and a case under the rule (these beans are from this bag), whereas the conclusion is obtained by applying the general rule to the particular case (these beans are white). ${ }^{11}$ Inductive arguments, on the other hand, obtain a general rule (all the beans from this bag are white) from a number of cases of which certain facts are simultaneously true (these beans are from this bag, these beans are white). Finally, abduction is a kind of reasoning that could be described as the process of forming explanatory hypotheses' 12 or as an 'inference to the best explanation. ${ }^{13}$ Suppose we find a handful of white beans on a table next to a bag of beans, knowing, in addition, that all the beans from this bag are white. In that case, we are inclined to infer that the beans lying on the table came from the bag simply because this conclusion, if true, would best explain why these beans are white. Thus, abductive inferences produce causal knowledge insofar as the conclusions are explanatory of one or more of their premises. In the $A P o$, on the other hand, the premises are explanatory of the conclusion and not the other way around, which seems to invert the order in which arguments are supposed to produce knowledge.

This picture explains why the interpretation advanced by Jonathan Barnes (1969) has been so influential. Barnes argued that the APo are not meant to describe how scientists acquire knowledge, nor does it intend to account for scientific research. Instead, 'the theory of demonstration offers a formal account of how an achieved body of knowledge should be presented and taught. ${ }^{14}$ This solution is attractive. Without violating our intuitions about how causal knowledge is acquired, it explains why it is possible to learn things 'by demonstration': demonstrative arguments do not reflect the order in which the expert scientist reaches his explanations, but the order in which she imparts these explanations to her pupils.

\footnotetext{
11 See Pierce (Collected Papers; 2. 620).

12Pierce (Collected Papers; 5.172).

${ }^{13}$ Harman (1965).

14Barnes $(1969,147)$.
} 
However, if demonstrating were essentially a pedagogic procedure, it would not be good one. Aristotle makes it clear that the premises of a demonstration are more familiar and prior to the conclusion precisely because they are explanatory of it ( $\left.A P_{0} \mathrm{I} 2,71^{\mathrm{b}} 31-2\right)$. In this context, the explanatory priority of the premises corresponds to what Aristotle describes as priority 'by nature' and what is prior and more familiar 'by nature' ( not the same as what is prior and more familiar 'to us' ( $\pi \rho$ ò $\varsigma \dot{\eta} \mu \tilde{\alpha} \varsigma, A P_{0}$ I 2, $\left.71^{\mathrm{b}} 33-72^{\mathrm{a}} 5\right)$. The premises of a demonstration are not more familiar and prior to the conclusion in the sense of being obviously true and more likely to be accepted by someone who is not yet an expert on the subject in question. They are prior and more familiar 'by nature' insofar as they display the cause of

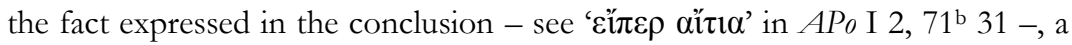
cause that not even the expert knows from the start, but grasps only after a complex procedure of inquiry. In other words, what counts as an dîtıov for Aristotle is prior to the phenomenon it explains in an objective sense and independently of the way the phenomenon was discovered in the first place.

To some extent, this is a problem of philosophical vocabulary. Foundationalism is usually depicted as a theory of how knowledge and true beliefs are justified, whereas Aristotelian explanations cannot be confounded with mere justification. Mere justifications provide answers to questions such as 'why do I believe that p?'. Aristotelian explanations, on the other hand, are meant to answer the question 'why is it the case that p?' (see GOLDIN 2013, 200). In order to justify my belief in a proposition $\mathbf{p}$, all I need is to set out the reasons why I believe in $\mathbf{p}$. On the other hand, for Aristotle, to present the aitiov of $\mathbf{p}$ is to identify a real-world item that is responsible for $\mathbf{p}$ being true (instead of being responsible for my knowledge that $\mathbf{p}$ is true). ${ }^{15}$ Premises that are explanatory in this strong sense are certainly not self-evident or knowable $a$ priori. Therefore, when interpreted according to the rationalist approach depicted above, Aristotle's foundationalism becomes incompatible with his own concept of explanation. If his solution to the dilemma of $A P o$ I 3 is to be labelled as a form of foundationalism at all, it seems preferable to specify what kind of foundationalism it is not in terms of justification, but in terms of causal explanations.

15 On the difference between justification and explanation, see Burnyeat (1981, 101); Goldin (2013, 200). For other interpretations that claim or assume that this is the notion of explanation present in Aristotle's theory of demonstration, see Kosman (1973); Matthen (1981); Taylor (1990, 120); McKirahan (1992, 209-31); Lesher (2001, 46); Charles (2000); Bronstein (2012; 2016); Angioni (2007; 2012; 2013; 2014; 2016). 


\section{A Non-Rationalist Account: from perception and induction to demonstration.}

The acquisition of first principles is the topic of the very last chapter of the APo. In II 19, Aristotle identifies 'the state that knows' ( $\dot{\eta} \gamma \nu \omega \rho$ í $\zeta o v \sigma \alpha$ $\approx ̋ \xi 1 \zeta, 99^{b}$ 18) principles with voṽ $\varsigma$, which is characterised as the most 'accurate'

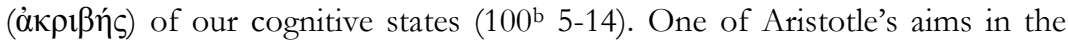
chapter is to address the following puzzle:

I have said earlier that you cannot understand anything through a demonstration unless you know the primitive immediate principles. As for knowledge of the immediates, one might wonder $[\ldots]$ whether the states, not being present in us, come about in us or rather are present in us without being noticed. It is absurd to suppose that we possess such states; for then we should possess pieces of knowledge more accurate than demonstration without its being noticed. But if we get them without possessing them earlier, how could we come to acquire knowledge and to learn except from preexisting knowledge? This is impossible, as I said in connection with demonstration [APo II 19, 99' 20-30; Barnes 1993 with changes].

Aristotle discusses two alternative hypotheses about the origin of our knowledge of first principles: either (i) it is already present in us without being

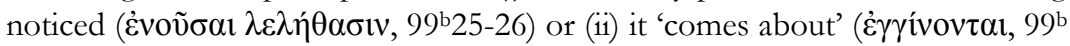
25 ) in us somehow. It is worth stressing that Aristotle does not consider the possibility of first principles being available to us from the beginning, as if they were self-evident propositions we could know without any heuristic procedure being required. On the contrary, if they are known to us at all - as in alternative (i) - we are not completely aware of them (along the lines of Plato's theory of recollection). ${ }^{16}$

Aristotle rejects alternative (i) on the grounds that such an 'accurate' cognitive state - even more accurate than demonstrative knowledge (99 $\left.{ }^{\mathrm{b}} 27\right)$ could not be present in us without us noticing them. As stated in hypothesis (ii), intelligence (võ̃s) must 'come about' in us, which in this context implies that first principles are acquired by a process of learning $\left(\mu \alpha v \theta \alpha\right.$ óvou $\mu \varepsilon v, 99^{\mathrm{b}}$ 29). Since there cannot be learning except from pre-existing knowledge $\left(99^{\mathrm{b}}\right.$ 28-30) - as the very first sentence of the $A P o$ makes it clear ( $A P_{0} \mathrm{I} 1,7^{\text {a }} 1-2$ ) -, 'the state that knows' first principles is not a fundamental cognitive state in the sense of not being based on previous knowledge of any kind. This preexisting knowledge, however, cannot be 'more valuable (...) in respect of

16 Some interpreters take hypothesis (i) as referring to Platonic innatism. See Barnes (1993, 261); Bronstein (2012, 38-39; 2016, 234). 
accuracy' (99 $33-340$ ) than voũ $\varsigma$, since voũ $\varsigma$ is the most accurate of all cognitive states.

Therefore, the task Aristotle takes on in APo II 19 is to indicate a state or capacity that, despite being less accurate than intelligence or demonstration, can at least initiate the process that leads us towards these higher forms of knowledge ${ }^{17}$.

Aristotle goes on to claim that this initial state is a 'connate

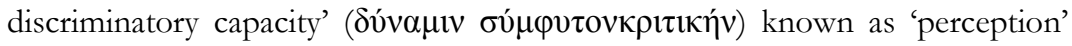

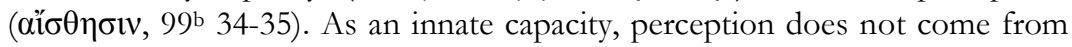
pre-existing knowledge nor is it a result of intellectual learning ( $\mu \alpha \dot{\theta} \theta \eta \sigma \varsigma \varsigma$ $\delta ı \alpha$ о $\tau \imath \kappa \eta)$. Therefore, the principle stated in the opening lines of the APo no longer threatens Aristotle's theory with infinite regress, since it does not apply to the capacity that initiates scientific inquiry. However, a feature common to all animals such as perception $\left(99^{\mathrm{b}} 34\right)$ is certainly not enough to give rise to a sophisticated form of knowledge such as voũ $\zeta$, which means the acquisition of first principles requires co-operation with other capacities. First, Aristotle recognises 'memory' $(\mu v \eta \dot{\mu} \eta)$ as indispensable to the process, since the information gathered by perception must be retained in our souls in some way (100a 3-4). Second, several memories of the same thing must be collected and compared with one another, which is made possible by a capacity Aristotle calls 'experience' ('̇ $\left.\mu \pi \varepsilon ı \rho^{\prime} \alpha, 100^{a} 4-6\right) .{ }^{18}$ Experience, in turn, allows us to grasp

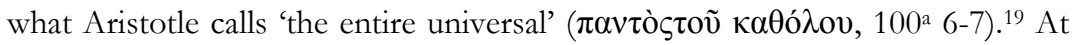
some point, this process ends up with the acquisition of voṽ $\left(100^{\mathrm{b}} 12-14\right)-$

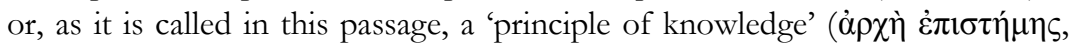
$100^{\text {a }} 8$; cf. $100^{\text {b } 12-14) . ~}$

We might think that, by tracing the acquisition of first principles back to perception, Aristotle prevents us from understanding his theory of demonstration along the lines of the rationalist interpretation sketched in the previous section. However, the capacities discussed in $99^{\mathrm{b}} 34-100^{\mathrm{b}} 5 \mathrm{can}$ be understood as parts of a process of concept-formation. ${ }^{20}$ If so, the proponent

\footnotetext{
17This description of Aristotle's aim in APo II 19 follows in general lines the interpretation advanced by Bronstein (2012; 2016, 225-247), who argues convincingly that the philosopher does not intend in this chapter to specify all the steps involved in the acquisition of first principles, but to defend that our knowledge of them originates in perception. For a similar view, see Kahn (1981). However, I disagree with Kahn and Bronstein in respect of the role of induction in the acquisition of first principles, as will become clear soon.

${ }^{18}$ See Metaphysics I 1, 980 b 28-982a 1 . Cf. Ferejohn $(2009,69)$, who characterises experience as 'the ability to classify retained percepts into general kinds.'

19 I shall set aside the question of whether 'the grasp of the universal' is intrinsic to experience (see Ross 1949, 674; Barnes 1993, 264) or a further, independent step in the acquisition of first principles (see McKirahan 1992, 243; Bronstein, 2012, 44-46; 2016, 237-240).

20 See Barnes (1993, 264-265); Ross (1969, 675-676). On this question, see Kahn (1981, 391-395); McKirahan (1992, 246); Charles (2000, 264, n. 37); Bronstein (2012, 58, n. 67; 2016, 246, n.63).
} 
of the rationalist interpretation might argue that the first principles we grasp by the end of this process are nothing more than propositions specifying the meaning of conceptual terms to be used in scientific discourse.

This reasoning is a non sequitur. From the fact that perception, memory and experience might be relevant to concept-formation it does not follow that the first principles of science are a priori self-evident propositions or that voṽ is nothing more than an intuitive grasp of the meaning of conceptual terms. ${ }^{21}$ In this chapter, Aristotle is primarily engaged in the task of identifying an innate capacity that is not based on pre-existing knowledge and therefore can serve as a starting point in our journey towards higher forms of cognition. As has been argued, there might well be further steps between the last stages described in $99^{\mathrm{b}} 34-100^{\mathrm{b}} 5$ and the noetic knowledge of first principles, a gap Aristotle did not attempt to fill in APo II 19.22 Therefore, it is not safe to conclude, only based on $A P o$ II 19 , that the grasp of first principles is nothing more than a process of concept-formation.

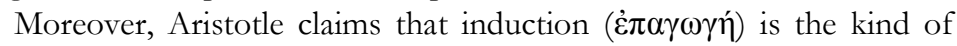
inference underlying the process by which we get from perception to the grasp of 'the entire universal' (100 $4-5$; with $100^{\mathrm{a}}$ 6-7). Therefore, it plays an important role in the acquisition of the first principles of science ( $\tau \dot{\alpha} \pi \rho \tilde{\omega} \tau \alpha$, $\left.100^{\mathrm{b}} 3-4\right) .{ }^{23}$ It is certainly true that inductive reasoning is part of the process of concept-formation. However, this is not the only, nor the most important role it plays in scientific inquiry. ${ }^{24}$ Aristotle seems to have recognised this fact in $A P r$ II 23, where he offers a sophisticated account of the kinds of reasoning involved in the discovery of scientific explanations. Contrary to expectations, his account is significantly close to the one proposed by contemporary philosophers of science:

Induction, then - that is, a deduction from induction - is deducing one extreme to belong to the middle through the other extreme, for example, if B is the middle for A and C, proving $\mathrm{A}$ to belong to $\mathrm{B}$ by means of $\mathrm{C}$ (for this is how we produce inductions). For instance, let $\mathrm{A}$ be long-lived, $\mathrm{B}$ stand for not having bile, and $\mathrm{C}$ stand for a particular longlived thing, as a man, a horse, or a mule. Now, A belongs to the whole $\mathrm{C}$ (for every $\mathrm{C}$ is long-lived); but B (not having

\footnotetext{
${ }^{21}$ Lesher $(1973,61)$.

22 See Kahn (1981, 396-397); Bronstein (2012; 2016, 225-247).

${ }^{23}$ In order to avoid the consequence that induction is all it takes to know the first principles, Bronstein $(2012,53-54 ; 2016,242)$ argues that ' $\tau \hat{\alpha} \pi \rho \tilde{\omega} \tau \alpha^{\prime}$ in $100^{\text {b }} 4$ denotes something else (in his words, 'first universals' and 'preliminary accounts'). However, in APo II 19, 100 $3-4$, the dative 'E் $\pi$ ' $\gamma \omega \gamma \tilde{n}$ ' does not necessarily mean that induction is sufficient for coming to know the items Aristotle calls ' $\tau \dot{\alpha} \pi \rho \tilde{\omega} \tau \alpha$.' Therefore, it is possible to interpret ' $\tau \dot{\alpha} \pi \rho \tilde{\omega} \tau \alpha$ ' as referring to the first principles of science without committing Aristotle to the view that induction is a sufficient condition for grasping them.

24 I therefore disagree with Kahn $(1981,396)$ and Bronstein $(2012 ; 2016,243)$, who limits the use of inductive inferences to the acquisition of nominal definitions.
} 
bile) belongs to every $\mathrm{C}$. If, then, $\mathrm{C}$ converts with $\mathrm{B}$ and the middle term does not reach beyond the extreme, then it is necessary for $\mathrm{A}$ to belong to $\mathrm{B}$ : for it has been proved earlier that if two terms belong to the same thing and the extreme converts with one of them, then the other of the predicates will also belong to the term that converts with it. (But one must understand $\mathrm{C}$ as composed of every one of the particulars: for induction is through them all.) [ $A P r$ II $23,68^{\mathrm{b}}$ 15-29; Smith 1989 with changes].

In this passage, Aristotle is primarily concerned not with 'induction' (ं் $\pi$ $\alpha \omega \gamma \eta \dot{)}$ ) properly speaking but with an argument derived from it - here

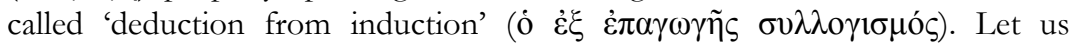
examine Aristotle's example.

Scientists investigate biological phenomena by having perceptual contact with certain animals ( $\alpha$ ï $\sigma \theta \eta \sigma ı)$, retaining images of them $(\mu v \eta \mu \eta)$ and realizing that these animals instantiate certain properties with regularity $\left(\dot{\varepsilon} \mu \pi \varepsilon \rho^{\prime} \alpha\right)$. Let us suppose that, in this process, the biologist finds out a corelation between longevity and absence of bile in animals like humans, horses and mules. Eventually, an inductive procedure will indicate that all animals of a single kind are long-lived whenever their bodies do not contain a significant quantity of bile:

\section{Syllogism I (Induction):}

Longevity holds of bumans, borses etc., Being a K holds of bumans, borses etc. Longevity holds of all $K s$

\section{Syllogism II (Induction):}

Absence of bile holds of bumans, borses etc., Being a K holds of bumans, borses etc. Absence of bile holds of all $K s$

Relying on this result, the inquirer proceeds to an inference that could be described as an 'inverted demonstration', where the explanatory term is not the middle, but the major extreme: ${ }^{25}$

\section{Syllogism III (Abduction):}

Longevity holds of all animals of the kind $K$, Being bileless holds of all animals of the kind $K$ Longevity holds of all bileless animals

In fact, the co-occurrence of longevity and absence of bile made Aristotle believe that, in certain animals, the latter is the explanation of the

\footnotetext{
25 The terms called 'middle' and 'extreme' in APr II 23, 68 15 -18 do not match the roles they play in the syllogism discussed in the passage, which means that these expressions are used as rigid designators of the middle term and the extremes of a demonstrative syllogism. See Ross (1949, 484-485).
} 
former. ${ }^{26}$ Thus, in the argument above, the explanans appears in the conclusion while the explanandum occurs in the major premise - an inference one could classify as abductive. However, while the so-called inferences to the best explanation' are non-deductive, Aristotle believes that, if the induction that precedes it is sufficiently comprehensive, we can obtain a deduction to the best explanation. Lines $68^{\mathrm{b}}$ 24-27 refer back to $A P r$ II 22, 68 21-25, where Aristotle has shown that if two terms A and B hold of all C, and C also holds of all $\mathrm{B}$, then $\mathrm{A}$ necessarily holds of all $\mathrm{B}$. Therefore, if the induction shows us that all and only the members of the relevant kind are bileless - and perhaps this is what Aristotle means by the enigmatic phrase 'the entire universal' in

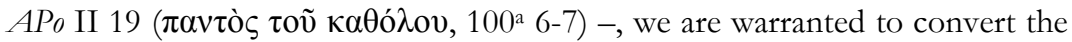
previous major premise and obtain 'a deduction from induction' concluding that all bileless animals are long-lived:

\section{Syllogism IV (Deduction from Induction):}

Longevity holds of all animals of a kind $K$, Being a $K$ holds of all bileeless animals Longevity holds of all bileless animals

Apparently, in $A P r$ II 23, Aristotle offers an account of the acquisition of explanations which is (to a certain extent) close to the one advanced by modern philosophers of science. However, none of the steps

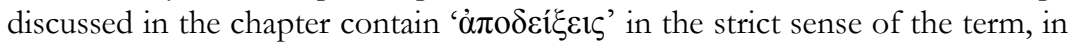
which the explanation occurs as the middle term:

\section{Syllogism V (Demonstration):}

Longevity holds of all bileless animals, Being bileless holds of all animals of the kind $K$ Longevity holds of all animals of the kind $K$

Thus, the chapter leaves us without an answer to the question of how exactly can scientists learn by demonstration.

Interpreters such as Kosman (1973, 383) and McKirahan (1992, 243) distinguish between knowing an explanation and knowing an explanation as such. Based on this distinction, David Bronstein has recently argued that there is a sense in which it is possible to learn by demonstration: if $\mathbf{p}_{\mathbf{1}}$ is explained by $\mathbf{p}_{2}$, demonstration is the reasoning by which a scientist learns that $\mathbf{p}_{\mathbf{2}}$ is actually explanatory of $\mathbf{p}_{1}$ (and not simply that $\mathbf{p}_{2}$ is the case). ${ }^{27}$ Let me endorse

\footnotetext{
${ }^{26}$ Parts of Animals IV 2, 676 $30-677^{\mathrm{b}} 10$.

${ }^{27}$ Learning by demonstration, I suggest, does not consist in deducing a new conclusion from known premises. Rather, it consists in discovering a previously unknown explanatory connection among facts the scientist already knows but not scientifically. Prior to learning, she knows $x$ and $y$, where $y$ is the explanation of $x$ and $x$ is explained by $y$, but she does not know $x$ or $y$ as such. She learns by demonstration when she apprehends $y$ as explanatory of $x$, or-what is the same thing $-x$ as explained
} 
Bronstein's interpretation in the following terms. Inductive and abductive arguments merely make it reasonable to accept their conclusions as true, since what they infer is not a necessary consequence of their premises. On the other hand, the argument Aristotle calls 'deduction from induction', despite having premises that do necessitate the conclusion, does nothing more than establish that the explanansis true, which is quite different from establishing that it is the adequate explanation of the explanandum in question. ${ }^{28}$ Knowing that all bileless animals are long-lived is different from knowing that this is the reason why horses and mules are long-lived.For Aristotle, only the second case is qualified as scientific knowledge and only demonstrations are able to provide it. A true expert scientist not only assents to a set of true propositions, but also organizes it in terms of explanatory priority. By demonstrating a given proposition taken as an explanandum, she not only knows that the correspondent explanans is true, but also realizes that the explanandum follows from the explanans and organizes her discourse accordingly, choosing as premises propositions that are explanatorily prior to the respective conclusions.

The question of how exactly we are able to recognize causal connections in the world does not seem to have bothered Aristotle (in the same way as it has bothered Hume, for instance). As a result, he never explains in a clear way (as far as I know) how the scientist realizes that a proposition $\mathbf{p}_{1}$ is explanatory of $\mathbf{p}_{2}$. However, if my interpretation of $\operatorname{APr}$ II 23 is correct, we can at least affirm that this recognition occurs at some point between Syllogism IV and Syllogism V. If it happens after Syllogism IV, by the time the scientist recognizes $\mathbf{p}_{1}$ as explanatory of $\mathbf{p}_{2}$, she already knows that $\mathbf{p}_{1}$ and $\mathbf{p}_{\mathbf{2}}$ are true. Therefore, what she learns 'by demonstration' cannot be the truthvalue of problematic propositions. One the other hand, if the recognition of causal relations happens before Syllogism V, one might object that demonstration is not the reasoning by which the scientist learns that something is causally prior to another, but just a way of exposing this causal priority in scientific discourse. If so, there is nothing the expert scientist really learns 'by demonstration'. How then are we supposed to understand Aristotle's use of the expression 'learning by demonstration'? Let me suggest the following solution. The term 'demonstration' is ambiguous: in one sense of the term, 'demonstration' is the name of a reasoning (a proof-search procedure, one could say) in which a scientist tries to identify propositions (already known to be true) from which a given conclusion(also known to be true) can be deduced and explained; in another sense, 'demonstration' is just the name of the syllogistically structured sequence of sentences that results

by $y$. As a result of her learning, she now has scientific knowledge of $x$, which she previously knew only non-scientifically [Bronstein 2012, 14].'

${ }^{28}$ See Kosman (1973, 383); McKirahan (1992, 243). Bronstein (2014, 14; 2016, 39-40). 
from this procedure. ${ }^{29}$ In the first sense, Aristotle could say that expert scientists learn 'by demonstration' without contradicting his claim that knowing that the explanandum is true is a necessary condition for investigating the explanans. The acquisition of demonstrative knowledge involves overcoming the ordo cognoscendi and making scientific discourse reproduce the ordo essendi; to demonstrate (in the first sense of 'demonstration') is to realize that and how this is possible.

Finally, it is worth noting that even though Aristotle requires the explanandum to be a logical consequence of the explanans, his theory remains quite different from the deductive-nomological models of explanation. For him, what makes a scientific proposition prior to another is something more than their difference in generality or the inferential connections between them ( $A$ Po I 13, 78 22-b3; II 16, 98 ${ }^{\text {b } 16-24) . ~ A s ~ w e ~ c a n ~ s e e, ~ d e m o n s t r a t i o n s ~ i n c l u d e ~}$ as premises the same sentences we would find in abductive arguments, but the inference goes in the opposite direction. The inferential steps discussed in $\mathrm{APr}$ II 23 enable the scientist to grasp a set of true propositions, whereas in the demonstrative stage this body of truths is organized in terms of causal priority - that is, priority 'by nature.' In other words, a demonstration of a conclusion $\mathbf{c}$ allows us to know not only (i) that $\mathbf{c}$ can be logically derived from a set of true premises $\Pi$ but also (ii) that $\Pi$ presents the set of factors responsible for c being true (which are prior to $\mathbf{c}$ 'by nature'), instead of the factors which make us believe that $\mathbf{c}$ is true (which are prior to $\mathbf{c}$ only 'relative to us') ${ }^{30}$.

\section{Interdependence between voṽ $\varsigma$ and demonstrative knowledge}

What about our knowledge of first principles? Some authors have pointed out that to understand first principles - that is, to have voṽ $\varsigma$ of them is to understand them as principles. ${ }^{31}$ As we know, first principles are nothing

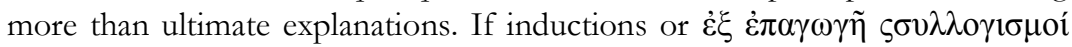
do not make us know explanations as explanations, the same should apply to first principles as first principles. But what does it mean to know a principle as

${ }^{29}$ Bronstein $(2016,41)$ seems to reply to this objection with a similar distinction between two senses of 'demonstration' - although it is not completely clear to me whether the senses of 'demonstration' he briefly discusses are the same two senses I have tried to discriminate.

${ }^{30}$ For the differences between Aristotle's and the 'covering law' theory of scientific explanation, see McKirahan (1992, 230-231). See also Brody (1972) for the advantages of the former over the latter.

${ }^{31}$ Kosman $(1973,389)$ argues: '[...] the noetic grasp we have of them [first principles] as principles concerns our ability to use them in explaining and making intelligible the world of phenomena. Noũ $\varsigma$ therefore is a feature of our understanding of all explanatory principles or premises [...] just insofar as we understand them in the act of explaining by them, i.e. just insofar as we understand them qua principles and not qua explicanda [emphasis in original].' See also McKirahan (1992, 243-244). 
principle? Based on our discussion so far, we can define an Aristotelian first principle in the following terms:

Def. (First Principle): $\mathrm{p}$ is a first principle iff.

(i) there is an Aristotelian demonstration $\langle\boldsymbol{\Pi}, \mathbf{c}\rangle$ such that $\mathbf{p}$ belongs in $\Pi$

(ii) there is no set $\Psi$ such that $\langle\Psi, p\rangle$ is an Aristotelian demonstration of $\mathbf{p}$.

According to this definition, to know a principle $\mathbf{p}$ as a first principle is to know that $\mathbf{p}$ satisfies conditions (i) and (ii). Whereas condition (ii) accounts for the indemonstrability of first principles, condition (i) states that a principle is always a principle of something. In APo I 2, 71 b 19-22, Aristotle lists six features of demonstrative principles: they are 'true and primitive and immediate and more familiar than and prior to and explanatory of the conclusion' (APo I 2, 71 b 19-22). At least three of these features are relative to a conclusion: 'more familiar than', 'prior to' and 'explanatory of.' ${ }^{2}$ Therefore, to grasp a first principle as such is to understand it as an indemonstrable premise from which one or more conclusions are demonstrated.

This result is in accordance with part of the secondary literature, which claims that both noetic and demonstrative knowledge involves a holistic outlook of a given body of truths. Interpreters such as Kosman (1973) and

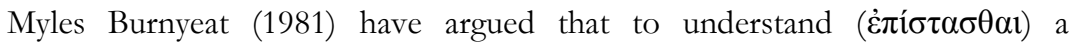
proposition $\mathrm{p}_{\mathrm{i}}$ is to determine its place in a complex web of interrelated propositions $\mathbf{p}_{1}, \mathbf{p}_{2}, \ldots, \mathbf{p}_{\mathbf{n}}$ organized in terms of explanatory priority, either as a first principle (noetic understanding) or as a theorem (demonstrative understanding). ${ }^{33}$ Along the same lines, McKirahan (1992, 243-244) affirms: 'to

32 See McKirahan (1992, 243); Ross (1949, 509); Barnes (1993, 93). Ferejohn (2009, 78-79) criticises McKirahan for being 'apparently impressed by Aristotle's use of comparatives in APo I 2, 71b 19-22.' Alternatively, he takes the three 'relational' conditions as reducible to a single 'absolute' condition: 'intelligibility in nature.' However, the notion 'intelligibility in nature' seems more obscure than the conditions it is supposed to clarify. More significantly, Aristotle explicitly takes the condition 'being explanatory of' as the fundamental one (APo I 2,71 b 29-33). The fact that these three requirements are relational does not imply that 'there are no objective and context-independent features that make somethings acceptable as principles and other things not' (FEREJOHN, 2009, 78). Since Aristotle is not concerned with mere justification (as Ferejohn seems to assume), what makes something a principle in his theory is something objective: the causal order of the reality. In other words, the principles are relational in the sense of being prior to other propositions, but objective in the sense of being prior 'in nature' and not 'relative to us.' For an approach that expands this 'relational' aspect of the notion of principle to the other requirements and to its 'necessity', see Angioni (2012) and Angioni (2014), respectively.

${ }^{33}$ Ferejohn $(2009,75)$ objects that interpretations like Kosman's associate Aristotle with coherentism, in opposition to the foundationalist view advanced in the APo. In the same vein, one could say that our interpretation also commits Aristotle to some sort of coherentism. However, we would be ascribing a coherentist doctrine to Aristotle only if we were saying that organizing scientific propositions in a coherent 
grasp something as a principle is to understand how the things of which it is a principle depend on it. [...] Thus, knowing principles entails appropriate knowledge of non principles.'

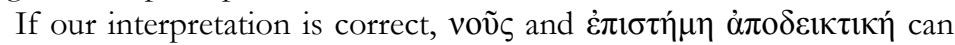
be considered interdependent in a certain way. Demonstrative knowledge in the strict sense involves knowing not only the proximate causes of a given phenomenon, but the ultimate ones as well. In other words, if $\langle\Pi, c\rangle$ is a fullfledged demonstration, there must be a subset of $\Pi$ containing only

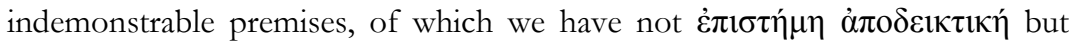

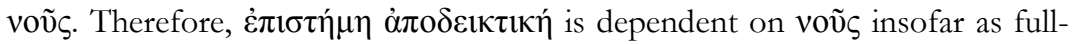
fledged demonstrative knowledge is impossible without intelligence of first principles. Nevertheless, a proposition cannot be considered a first principle of science independently of their explanatory roles in demonstrations. If voũ $̧$ is the knowledge of first principles as first principles, its acquisition depends on figuring out their position in the body of science as a whole, which involves the practise of demonstrating other, less basic propositions from them. Therefore, if APo II 19 does not account for all the steps involved in the acquisition of first principles, this gap is filled by the very practise of demonstrating - where 'demonstrating' is to be understood in our first sense of 'demonstration' (i.e. the reasoning underlying a proof-search procedure).

Such account of the relation between voũ $\varsigma$ and $\dot{\varepsilon} \pi \iota \tau \eta \dot{\mu \eta}$

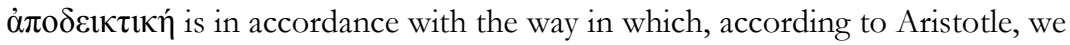
come to know definitions. In $A P$ II 10 , the philosopher distinguishes definitional sentences that are mere accounts of meaning (93 $19-37$ ) - or 'nominal definitions' - from definitions as accounts of essence - or 'real definitions' (93 38 -94 7 ). According to Aristotle, a definition of the second kind is 'an account which displays the reason why' ( $\lambda \hat{o} \gamma \circ \varsigma$ ó $\delta \eta \lambda \tilde{\omega} v \delta i \grave{\alpha} \tau i ́$ $\left.\varepsilon \check{\sigma} \sigma \tau v, 3^{\mathrm{b}} 39\right)$. We know first principles are not self-evident propositions from which problematic beliefs can be justified, but causal explanations acquired after a complex process of inquiry (involving perception, memory, experience, induction etc.). Therefore, in virtue of their causal or explanatory content, real (and not merely nominal) definitions are the propositions playing the role of first principles in Aristotle's theory. In APo II 8-10, it becomes clear that causal definitions of this sort are not grasped independently of the practise of demonstrating, as I shall argue now.

body is the method by which scientists get to know explanatory relations. This is not what I am proposing - and, if I understand his interpretation correctly, neither is Kosman. What requires a holistic understanding of the body of scientific truths is not the recognition of a particular explanatory relation between two propositions, but the recognition of first principles as such - after all, figuring out that $\mathrm{p}$ is a principle involves realizing that there is no other proposition from which $\mathbf{p}$ can be demonstrated. I am grateful to an anonymous referee on this issue. 
In $A P$ III, Aristotle engages in a long discussion about whether or not definitions can be demonstrated. His final answer is negative. Although it is possible to elaborate sound syllogisms whose conclusions are definitional sentences, such arguments are merely 'logical' ( $\lambda$ o $\gamma$ ikòs), without real explanatory force ( $A P_{0}$ II $8,93^{a}$ 9-15). After denying that definitions can be conclusions of demonstrations ( $A P_{0}$ II $8,93^{a}$ 9-15), Aristotle announces his aim in $A P_{0}$ II 8: 'let us say in what way a demonstration [of what something is] is possible, starting again from the beginning' (93a 15-16). 'Starting again from

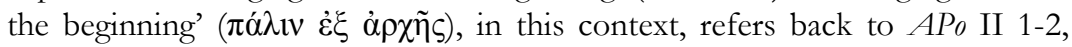
where Aristotle recognizes equivalencies between the following four questions:

(Q1) Does P holds of S? E (Q3) Does P exist?

(Q2) Why does P holds of S? E (Q4) What is P?

Additionally, the philosopher affirms that these questions can be reduced to questions about a middle term: why $\mathrm{PaS}$ ?

(Q1/Q3) Is there an $\mathrm{M}$ such that PaM, MaSrPaS\& $\mathrm{M}$ is the reason

(Q2/Q4) What is M such that PaM, MaStPaS\& M is the reason why $\mathrm{PaS}$ ?

From these equivalencies, it follows that there is an isomorphism between the definition of $\mathrm{P}$ and the explanation of $\mathrm{S}$ being $\mathrm{P}$. For instance, we explain why the specific noise we call 'thunder' holds of clouds through the middle term 'extinction of fire' ( $A P_{0}$ II 8, 93a 7-b14):

\section{Syllogism VI:}

Noise holds of extinction of fire, Extinction of fire holds of clouds Noise holds of clouds

Thus, if we rearrange Syllogism VI in a propositional structure, we get the definition of thunder:

Thunder is (df.) noise of fire being extinguished in the clouds (APo II 10, 94a 5-6).

Even if Syllogism VI is not a demonstration of a definition - in the sense of having a definition as its conclusion -, it displays or reveals the essence of thunder. Therefore, Aristotle can conclude his reasoning as follows:

We have said how what something is taken and becomes familiar. Although there are no syllogisms and no demonstrations of what something is, nevertheless what something is made plain through syllogisms and through demonstrations. Hence without a demonstration you cannot 
get to know what something is [APo II 8, 93 $3^{\mathrm{b}}$ 15-18; Barnes 1993].

The isomorphism between the definition of thunder and Syllogism VI is not just a coincidence of results of two independent scientific practises: defining and explaining. On the contrary, we cannot know the essence of something independently of the explanatory role it plays in a demonstration:

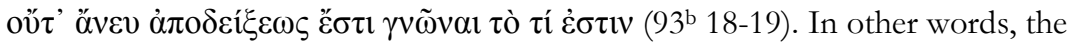
way we acquire knowledge of definitions intrinsically involves the act of explaining phenomena by demonstration. ${ }^{34}$

However, in $A P o$ II 9,93b 21, Aristotle affirms that only the essence of things 'whose cause is something different' is made clear through demonstrations $\left(93^{\mathrm{b}} 25-28\right)$. It has been argued that this passage is meant to show that the interdependence between defining and explaining holds good for the essence of processes and attributes such as thunder and eclipse (whose essences would be causally complex), but not the essence of substances such as human or moon (whose essences would be causally simple). ${ }^{35} \mathrm{I}$ believe this interpretation is mistaken for the following reasons.

First, Aristotle's own examples in APo II 8, 93a 22-24, include 'human' and 'soul', which suggests that the isomorphism between definition and demonstration applies to substances as well. ${ }^{36}$ In fact, in Metaphysics VII 17 and VIII 2-4, Aristotle explicitly extends the model presented in the Analytics to include substance-kinds. As we saw, the question 'what is thunder?' can be analysed as 'why does such-and-such noise happens to the clouds?'. Similarly, the question 'what is a human being?' is equivalent to 'why is this kind of body arranged in such-and-such way?' This last question is answered by a syllogism of the following form:

\section{Syllogism VII:}

This arrangement holds of being rational soul, being a rational soul holds of this type of body This arrangement holds of this type of body.

Correspondingly, the definition of human being would run as follows:

Human beingis (df) a body arranged in such-and-such way for the sake of being a rational soul. ${ }^{37}$

On the other hand, the example of an 'item whose cause is not something else' offered in the chapter is 'unit', which suggests that the

\footnotetext{
34 See Kung (1977, 168-172); Charles (2000; 2010; 2014); Williams \& Charles (2013); Peramatzis (2011, 180-188; 2013); Angioni (2012; 2014).

${ }^{35}$ Ross (1969, 633); Bronstein (2016, 131-143).

${ }^{36}$ Peramatzis $(2011,11)$.

${ }_{37}$ See Charles (2000; 2010, 268-328); Peramatzis (2011, 180-200; 2013, 303-305).
} 
exceptions to the interdependence of defining and explaining are conceptually simple notions, rather than hylemorphic compounds.

Moreover, and more importantly, our main thesis remains true even for definienda such as 'unit': although its definition is merely 'supposed' by arithmeticians and not discovered through any demonstrative practise $\left(93^{\mathrm{b}} 22^{2}\right.$ 25), its status as a first principle depends on its being used to explain arithmetic theorems. Consequently, even if Aristotle did not recognised in the $A P o$ an isomorphism between definition and demonstration in the case of substances, there is a way in which the scientific practises of defining and explaining would remain interdependent. This result is supported by a famous passage in De Anima I 1:

It seems that not only is ascertaining what a thing is useful for considering the causes of the properties of substances $[. .$.$] ,$ but also, conversely, that ascertaining the properties of a substance plays a great part in knowing what a thing is. [...] For the principle of every demonstration is what a thing is, so that those definitions which do not lead us to ascertain the properties of a substance, or at least to know them in a ready sort of way, will clearly and in every case be dialectical and vacuous [De Anima I 1, 402 b 16-403a 2; Shields 2016 with changes].

In this passage, Aristotle is relying on the claim that what characterizes the essence of a substance - in comparison with other necessary (but non-essential) properties - is its being explanatorily basic, i.e. their presence in the substance explains the substance's having other derivative properties, but is not explained by any other property the substance may have. Thus, to know the essence of a substance as the essence of that substance involves realizing that it is explanatory of its demonstrable attributes. Similarly, to recognize a proposition as an authentic definition (and not merely 'dialectical and vacuous') involves realizing that certain phenomena can be demonstrated from them. This result is in accordance with our account of the relation between demonstrative knowledge and voũ s. Noṽ $s$ is the cognitive state that knows definitions. Since demonstrations are based on definitions, demonstrative knowledge is dependent on voũs. However, if we cannot get to know a definition independently of the act of demonstrating, one cannot have voũ without having demonstrative knowledge. The interdependence of these two kinds of knowledge just mirrors the interdependence between defining and explaning. 


\section{Objections and Replies}

Let me now address some objections than might be raised against my proposal. I have claimed that to have voũ of first principles is to know them as first principles, which involves understanding them as satisfying all the six requirements mentioned in $A P_{0} \mathrm{I} 2,71^{\mathrm{b}}$ 19-22, including the relational ones: being 'more familiar than...', 'prior to...' and 'explanatory of...' David Bronstein (2016, 62-63) has argued that if this is so, voṽ

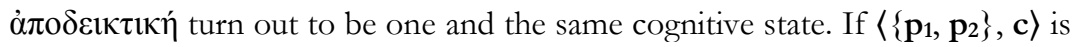
a demonstration, having demonstrative knowledge of $\mathbf{c}$ is to know $\mathbf{c}$ as explained by premises $\mathbf{p}_{1}$ and $\mathbf{p}_{2}$. On the other hand, to know that $\mathbf{p}_{1}$ and $\mathbf{p}_{2}$ satisfy the relational criteria is to know them as explanatory of $\mathbf{c}$. However, 'knowing $\mathbf{c}$ as explained by $\mathbf{p}_{1}$ and $\mathbf{p}_{2}$ ' and 'knowing $\mathbf{p}_{1}$ and $\mathbf{p}_{2}$ as explanatory of c' are, according to him, 'two descriptions of the same cognitive state'. ${ }^{38}$

However, my claim is that having voṽ $\varsigma$ of $\mathbf{p}_{1}$ and $\mathbf{p}_{2}$ involves determining their places in a given body of interrelated propositions and realizing that: (i) there are no propositions within it from which $\mathbf{p}_{1}$ or $\mathbf{p}_{2}$ can be demonstrated; (ii) there are one or more propositions that can be demonstrated from $\mathbf{p}_{1}$, as well as there are one or more propositions that can be demonstrated from $\mathbf{p}_{2}$ - leaving it open whether $\mathbf{p}_{1}$ or $\mathbf{p}_{2}$ can be used to demonstrate the same proposition. ${ }^{39}$ Thus, voũ $s$ depends on there being demonstrative knowledge of one proposition or other. That being said, we can reply to this first objection as follows. If $\mathbf{p}_{1}$ and $\mathbf{p}_{2}$ are the first principles from which $\mathbf{c}$ is demonstrated, having demonstrative knowledge of $\mathbf{c}$ requires having noetic knowledge of $\mathbf{p}_{1}$ and $\mathbf{p}_{2}$. Nevertheless, although noetic knowledge of $\mathbf{p}_{1}$ and $\mathbf{p}_{2}$ requires a comprehensive understanding of a given body of truths (and the explanatory role of $\mathbf{p}_{1}$ and $\mathbf{p}_{2}$ within it), it does not require knowing $\mathbf{p}_{1}$ and $\mathbf{p}_{2}$ as explanatory of $\mathbf{c}$ specifically. Therefore, even if the expressions 'knowing $\mathbf{p}_{1}$ and $\mathbf{p}_{2}$ as explanatory of $\mathbf{c}$ ' and 'knowing $\mathbf{c}$ as explained by $\mathbf{p}_{1}$ and $\mathbf{p}_{2}$ ' describe the same piece of knowledge - a claim which is by itself controversial - 'knowing $\mathbf{p}_{1}$ and $\mathbf{p}_{2}$ as explanatory of $\mathbf{c}$ ' in which ' $\mathbf{c}$ ' stands for an determinate conclusion is not a good description of the kind of holistic cognition Aristotle calls 'voũ s.'

In fact, if the content of noetic knowledge of $\mathbf{p}_{1}$ and $\mathbf{p}_{2}$ could not be specified without mentioning a specific conclusion such as $\mathbf{c}$, it would be difficult to sustain that an expert scientist could learn by demonstration in the way we agreed she could. After all, if having voũ $\zeta$ of $\mathbf{p}_{1}$ and $\mathbf{p}_{2}$ already involves knowing $\mathbf{p}_{1}$ and $\mathbf{p}_{2}$ as explanatory of $\mathbf{c}$, the scientist will learn nothing when

\footnotetext{
${ }^{38}$ Bronstein $(2016,62)$.

${ }^{39}$ Certainly, clause (ii) does not require a demonstrative knowledge established previously and independently of voũs. Therefore, my view does not imply that there is one piece of demonstrative knowledge which is prior to voũç in time.
} 
she tries to demonstrate $\mathbf{c}$ from $\mathbf{p}_{1}$ and $\mathbf{p}_{2} \cdot{ }^{40}$ On the other hand, if coming to know $\mathbf{p}_{1}$ and $\mathbf{p}_{2}$ as principles involves realizing that there are true propositions that can be demonstrated from them (which are not necessarily $\mathbf{c}$ ), there is still room for discovering new explananda (possibly c) and trying to trace them back to the first principles. Let us consider, for instance, an expert biologist who discovered (through the inferences and capacities described in APo II 23 and APo II 19) that absence of bile causes animals such as horses, mules and camels to be long-lived. Let us also say that it has already been established that all these species are essentially blooded animals (which involves knowing that some of their properties are explained by their being blooded). If the biologist tries to explain their longevity from first principles, she will eventually find out that absence of bile is the cause of their being long-lived because the liver (of which bile is a residue) is vital and necessary to all blooded animals. Thus, she will have learned by demonstration that certain blooded animals are long-lived having previous noetic knowledge that their essence involves their being blooded. ${ }^{41}$

However, even if there is a way of distinguishing one cognitive state from the other, a second objection could be raised. In APo II 19, Aristotle

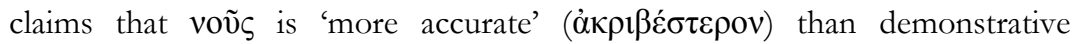
knowledge. One might argue that we cannot explain this claim if we take these two cognitive states as interdependent. On the other hand, the rationalist interpretation would take this claim in purely subjective terms: the first principles are self-evident and accepted as true without any justification, whereas the respective conclusions become evident to us only through the evidence of the principles. Thus, the rationalist interpretation is able to explain how the 'accuracy' of demonstrative knowledge depends on the 'accuracy' of voũ $\varsigma$ but not vice-versa.

First, the claim that voũ is the most 'accurate' type of knowledge does not need to be understood in subjective or psychological terms, as if the content of noetic knowledge were somehow 'more evident' than the content of other cognitive states. As we have seen, Aristotle describes the premises of

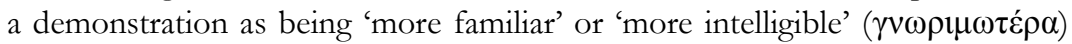
than the conclusion. At first sight, this vocabulary might suggest that our mental attitudes towards these premises are at stake. Nevertheless, the feature of demonstrative premises Aristotle wants to stress is fully objective: by 'more familiar' he means not 'more familiar to us' (a subjective notion) but 'more familiar by nature', which amounts to the objective notion of causal or explanatory priority (APo I 2, 71b 31). Lesher (2010), for instance, has convincingly argued that 'clarity' ( $\sigma \alpha \varphi \eta ́ v \varepsilon 1 \alpha)$ in Aristotle is not necessarily a

\footnotetext{
40 As Bronstein $(2016,65)$ himself notes.

${ }^{41}$ See Parts of Animals IV 2, 677 ${ }^{\mathrm{a}-\mathrm{b} 10}$. If this pattern describes Aristotle in his biological treatises, it might count as further evidence for my interpretation the fact it is in accordance with his scientific practise.
} 
psychological notion, the same being true for the notion of 'accuracy' ( $\tau$ ò

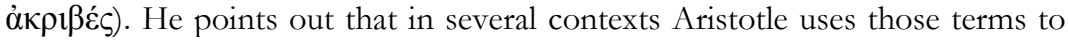
refer to 'the attainment of full scientific knowledge' (Lesher2010, 148-156). Now, as I have argued, if $\left\langle\left\{\mathbf{p}_{1}, \mathbf{p}_{2}\right\}, \mathbf{c}\right\rangle$ is the demonstration of $\mathbf{c}$, one cannot have demonstrative knowledge of $\mathbf{c}$ without having noetic knowledge of $\mathbf{p}_{1}$ and $\mathbf{p}_{2}$. However, having voṽ of $\mathbf{p}_{1}$ and $\mathbf{p}_{2}$ does not require demonstrative knowledge of $\mathbf{c}$ specifically. Therefore, the content of noetic knowledge (e.g. knowing $\mathbf{p}_{1}$ and $\mathbf{p}_{2}$ as principles) is more comprehensive and complete in comparison with the more specific content of the correspondent piece of demonstrative knowledge (e.g. knowing $\mathbf{c}$ as explained by $\mathbf{p}_{\mathbf{1}}$ and $\mathbf{p}_{2}$ ) - and this could be what Aristotle had in mind when he claimed that voṽ $\mathrm{s}$ is the most 'accurate' of all cognitive states.

\section{Concluding Remarks}

If 'foundationalism' is understood as a theory on epistemic justification - according to which we establish a given conclusion by deriving it from self-evident truths known by non-inferential procedures - Aristotle is not foundationalist. First, conclusions of demonstrations can be deduced from their respective premises and vice-versa, which means that the priority of the premises over the conclusion is not determined by inferential connections between them. Second, such priority cannot be explained in terms of evidence, since the premises are more familiar 'by nature' and not 'relative to us'. After all, the knowledge of first principles is the final result of a complex inquiry which has perceptual knowledge as its starting point. Third, the status of a proposition $\mathbf{p}$ as a first principle does not rely (primarily) on a feature that $\mathbf{p}$ has in itself, such as being self-evident or analytically true. Rather, it depends on $\mathbf{p}$ being explanatory of other propositions and no other proposition being explanatory oh p. Consequently, voṽ $\varsigma$ is not an intuitive grasp of self-evident propositions, which could be obtained independently of the practise of demonstrating conclusions from essence-specifying definitions. On the contrary, noetic and demonstrative knowledge are interdependent cognitive states in the same way as defining and explaining are interdependent scientific practises. If Aristotle can be correctly described as a 'foundationalist' in the first place, his 'foundationalism' amounts to the recognition of ultimate explanatory factors, a.k.a. 'essences'. ${ }^{42}$

\footnotetext{
${ }^{42}$ Many thanks to Lucas Angioni and Michailv Peramatzis for invaluable remarks on drafts of this paper. I am also thankful to Benjamin Morison for insightful questions and comments on some of my claims. A previous version of this article was presented at the conference Nature and Knowledge in Plato and Aristotle organized by Prof. Lucas Angioni at the University of Campinas. I am indebted to all participants, including Lucas Angioni, David Ebrey, Barbara Sattler, Vasilis Politis, Raphael Zillig, Daniel
} 


\section{References}

ANGIONI, L. (2007) "Conhecimento Científico no Livro I dos Segundos Analíticos de Aristóteles" Journal of Ancient Philosophy Vol. 1 (2).

ANGIONI, L. (2012) "Os seis requisitos das premissas da demonstração científica em aristóteles (Segundos Analíticos I 2)". Manuscrito (UNICAMP), v. 35 , p. 7-60.

ANGIONI, L. (2013) "Knowledge and Opinion about the same thing in APo A-33.” DoisPontos 10: 255-290.

ANGIONI, L. (2014) "Aristotle on Necessary Principles and on Explaining X through X's essence.”'Studia Philosophica Estonica 7.2: 88-112.

ANGIONI, L. (2016) "Aristotle's definition of scientific knowledge (APo71b 9-12)" Forthcoming on Logical Analysis and History of Philosopby 19:79-105.

BARNES, J. (1969) "The Aristotle's Theory of demonstration". Phronesis 14 (2): 123-152.

BARNES, J. (1993) Aristotle: Posterior Analytics. Translated with a commentary. 2ed. Oxford: Clarendon Press.

BRODY, B. A. (1972). "Towards an Aristotele an Theory of Scientific Explanation." Philosopby of Science 39 (1):20-31.

BRONSTEIN, D. (2012) "The Origin and Aim of Posterior Analytics II.19”. Phronesis 57 (1):29-62.

BRONSTEIN, D. (2014) “Aristotle's theory of demonstration revisited". Metascience 23: 1-35.

BRONSTEIN, D. (2016) Aristotle on Aristotle on Knowledge and Learning: The Posterior Analytics. Oxford University Press.

Nascimento, José Baraccat Júnior, Fernando Martins Mendonça, Felipe Weinmann, Wellington Damasceno de Almeida, and Gustavo Bianchi Ferreira. I am also grateful to the São Paulo Research Foundation (FAPESP), for financial support. Finally, I would like to thank the editor João Hobuss and two anonymous referees for their helpful comments and criticisms. 
BURNYEAT, M. (1981) "Aristotle on Understanding Knowledge". In: Berti, E. Aristotle on Science: The Posterior Analytics, Proceedings of the Eighth Symposium Aristotelicum (pp. 97-139). Padova: Editrice Antenore.

CHARLES, D. (2000) Aristotle on Meaning and Essence. Oxford: Clarendon Press.

CHARLES, D. (2010) "Definition and Explanation in the Posterior Analytics and Metaphysics" In: Charles, D. (ed.) Definition in Greek Philosophy. Oxford: Oxford University Press.

CHARLES, D. (2014) "Aristotle: definition, explanation, and essence." Metascience 23:1-35.

CORCORAN, J. (2009) “Aristotle's Demonstrative Logic". History and Philosophy of Logic 30(1), pp. 1-20.

FEREJOHN, M. (1991) The origins of Aristotelian science. New Haven: Yale University Press.

FEREJOHN, M. (2009) "Empiricism and First Principles in Aristotle". In: Anagnostopoulos, G. (ed.) A Companion to Aristotle (pp. 66-80). Chichester: Wiley-Blackwell.

FREDE, M. (1996) “Aristotle’s Rationalism”. In: Frede, M. \& Striker, G. (eds.) Rationality in Greek Thought. Oxford University Press: 157-173.

GOLDIN, O. (2013) "Circular justification and explanation in Aristotle." Phronesis 58, 195-214.

HARMAN, G. H. (1965). "The Inference to the Best Explanation." Philosophical Review 74 (1): 88-95.

IRWIN, T. (1988) Aristotle's First Principles. Oxford: The Clarendon Press.

KAHN, C."The Role of Nous in the Cognition of First Principles in Posterior Analytics II 19" In: Berti, E. Aristotle on Science: The Posterior Analytics, Proceedings of the Eighth Symposium Aristotelicum (pp. 385-414). Padova: Editrice Antenore.

KUNG, J. (1977) “Aristotle on Essence and Explanation" Philosophical Studies: An International Journal for Philosopby in the Analytic Tradition. 31 (6): 361-383. 
KOSMAN, L. (1973) "Understanding, Explanation and Insight in the Posterior Analytics". In: Lee, E.N. Mourelatos, A.P.D. \&Rorty, R.M. (eds.) Exegesis and Argument, Studies in Greek Philosophy presented to Gregory Vlastos. New York: Humanities Press.

LESHER, J.H. (1973) "The Meaning of Nous in the Posterior Analytics" Phronesis 18: 44- 68.

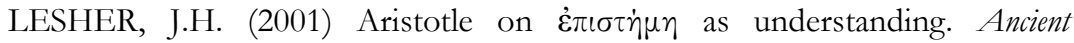
Philosophy 21, 45-55.

LESHER, J.H. (2010) “Saphêneia in Aristotle:'Clarity','Precision', and 'Knowledge'" Apeiron 43 (4):143-156.

MATTHEN, M. (1981) “The Structure of Aristotelian Science." In: Matthen, M. (ed.). Aristotle Today: Essays on Aristotle's ideal of science. Edmonton: Academic Printing \& Publishing, 1-23.

McKIRAHAN, R. (1992) Principles and Proofs. Princeton: Princeton University Press.

PERAMATZIS, M. (2011) Priority in Aristotle's Metaphysics. Oxford: Oxford University Press.

PERAMATZIS, M. (2013) "Science and Metaphysics in Aristotle's philosophy." Metascience 22 (2): 303-315.

PEIRCE, C. S. (1974) Collected papers. Vols. 1-6 edited by C. Hartshorne and P. Weiss; Cambridge: Belknap Press of Harvard University Press.

ROSS, D. (1949) Aristotle: Prior and Posterior Analytics, A Revised Text with Introduction and Commentary. Oxford: Clarendon Press.

SCHOLZ, H. (1975) "The Ancient Axiomatic Theory", In: Barnes, J.; Schofield, M.; Sorabji, R. (eds.) Articles on Aristotle, Vol.1: Science. (pp.50-64). London: Duckworth.

SHIELDS, C. (2016) Aristotle:De Anima. Oxford: Oxford University Press.

SMITH, R. (1989). Aristotle Prior Analytics. Cambridge: Hackett Publishing Company. 
TAYLOR, C. C. (1990) “Aristotle's Epistemology”. In: Everson, S. (ed.) (1990). Epistemology: Companions to Ancient Thought (Vol. I, pp. 116-142). Cambridge: Cambridge University Press.

WILLIAMS, S. \& CHARLES, D. (2013). "Essence, modality and the master craftsman." In: Feser, E. (ed.) Aristotle on Method and Metaphysics. (pp. 121-145) New York: Palgrave Macmillan.

Email: baz1289@gmail.com

Recebido: 09/2016

Aprovado: 11/2016 